DOI: https://doi.org/10.47405/mjssh.v6i9.972

\begin{tabular}{|c|c|}
\hline 4 & Malaysian Journal of Social Sciences and Humanities (MJSSH) \\
\hline $\begin{array}{l}\text { Malaysian Juoural of } \\
\text { Social ccciecces and }\end{array}$ & Volume 6, Issue 9, September 2021 \\
\hline (MJ-sSH) & e-ISSN : 2504-8562 \\
\hline & $\begin{array}{l}\text { Journal home page: } \\
\text { www.msocialsciences.com }\end{array}$ \\
\hline
\end{tabular}

\title{
Consumer Purchase Intention toward Online Food Delivery Service: The Implication for Future Research
}

\author{
Siti Anis Adilah Tarmazi ${ }^{1}$, Wan Rusni Wan Ismail ${ }^{1}$, Nur Aisya Syazwani Noor Azmin ${ }^{1}$, Ahmad \\ Redhuan Abu Bakar ${ }^{1}$ \\ ${ }^{1}$ Faculty of Hotel and Tourism Management, Universiti Teknologi MARA, Cawangan Pulau Pinang, Malaysia
}

Correspondence: Wan Rusni Wan Ismail (rusni.wi@uitm.edu.my)

\begin{abstract}
In Malaysia, online food delivery service provider has experienced steady growth in term of the increasing numbers of companies offering this service. This study aims to analyze consumer purchase intention towards online food delivery service based on factors of control, convenience, needs for interaction, technology anxiety, and consumer satisfaction. Additionally, this study highlighted which service delivery provider that are more preferred by consumers and help to identify the actual demographic profile and market segments for this service. This research was carried out using a quantitative approach and data was collected using a questionnaire and distributed through an online platform. Purposive sampling was used with screening questions. Sample size was determined using power analysis with total number of 147 respondents were identified as the appropriate minimum sample size for this study. The findings indicate intention of using an online food delivery provider is strongly influenced by independent variables tested in this study. However, findings from this study have shed some light concerning the demographic profile of consumers who use services from online service delivery. For instance, it is believed that this service is much more appealing to the younger generation due to their ability to adopt a new technology and the older generations are more resistant to changes. Thus, this study has proved that generation $\mathrm{X}$ are the heavy users of online food delivery service due to the advantages its offers in term of convenience and satisfaction. This indicates that these segments have less resistance to new technology and services.
\end{abstract}

Keywords: online delivery service, food purchase intention, attitude, consumer's profiling

\section{Introduction}

A new business model namely online food delivery service is where companies business revolved around delivery services and they do not provide any tangible products. The core service offered does not involve actual food preparation instead the service provided is online ordering platforms, tracking systems, and online payment (Pigatto et al., 2017). These services are unlike services offered by restaurants such as McDonald's, Kentucky Fried Chicken (KFC), and Pizza Hut where they are accountable for the preparation of the food until it is delivered to the consumer. The order will be fetched by the food delivery provider service's rider and being delivered to the consumer. Today the steady growths of online delivery service providers are driven by the consumers' intentions to use these services are gradually gaining popularity (Das, 2018). According to Acumen Research and Consulting (2021), Malaysia's online food delivery market is projected to reach over 319.1 Million USD by 2026. 
The restaurateurs will face new challenges with numerous advantages obtainable by online delivery services. For instance, they have to deal with the problem in measuring consumer satisfaction and service quality. In the conventional food and services setting, consumers consume food concurrently in restaurants. Hence, with the presence of third-party service providers, both tangible and intangible products are served by different parties. As a result, it is difficult to measure consumer satisfaction. As mentioned by Ilham (2018) consumer satisfaction and consumer loyalty are often found to have a strong relationship with service and food taste. Moreover, service qualities are difficult to measure as online product images are not accurate and actual. Thus, it is tough to know the weight, actual size, and value of the product (Hanus, 2016). It is hard to measure the quality of the product as consumers do not see the food visually and get the right food temperature due to delivery time when ordering food online.

Thus, this study aims to identify the effect of consumer's attitudes towards their intention to use online service delivery providers. This study analyses the relationship between control, convenience, need for interaction, technology anxiety, satisfaction of consumers, and online purchase intention. Apart from that, this study will also help in profiling consumers for the food delivery service segment and highlight the most sought-after service delivery providers in Malaysia.

\section{Literature Review}

\section{Online Delivery Service}

Recently, the popularity of food delivery service has gained strong momentum due to its various advantages offered by these services (Jacob et al., 2019, Ilham, 2018). More people have started to switch from buying food from the restaurant to online ordering and with availability of the internet and the use of the mobile phone have led to strong growth in the online service provider business (Gawande, Pachaghare, \& Deshmukh, 2019). Online delivery service does not only offer delivery service per se but other services come together with the delivery such as customize ordering services that allow consumers to choose from the list of menus, similar to those in an actual restaurant setting. On the other hand, for restaurateurs the online delivery services have offered a new dimension in the way of doing business. It's ability to remove all the burden that come together with the restaurant operation such as staffing and other overhead costs including the reduction of service and dining area (Chorneukar, 2014). In the attempt to understand how the consumers, perceive online food delivery in Malaysia, the theory of attitude is applied in this research to understand the underlying motivations towards the intention and future purchase using this service.

\section{Theory of Attitude}

The theory of attitude is one of the most common theories used in social science due to its application in behavioral study particularly in social science and business research. Attitudes are found to have a positive relationship with behavioral intention and such findings are found consistent throughout many cultures (Paul et al., 2016). Intentions are clues of how hard people are willing to try, how much of an effort they are planning to exert and to perform the behaviour; they are anticipated to capture the motivational factors that influence behavior (Ajzen, 1991). Attitude is one of the important variables in the behavioral study as this is the core element that directed one behavior as it is also the most consistent element in an individual. Furthermore, attitude is also found to be responsible towards heuristic or automatic decision making that are found mostly in low involvement decision making including food purchase (Gigerenzer and Gaissmaier, 2011). Factors such as convenience, interaction, technology anxiety and satisfaction are found to have a direct relationship with consumers' attitudes and the intention to use online food delivery service (Kimes, 2011).

\section{Convenience}

Convenience refers to the potential to scale back non-monetary transaction expenses like energy, time, and energy by using products and services or purchasing (Chang \& Polonsky, 2012). Convenience is 
decided by operating time, geographic location, and availability online, in-person, or by phone (Meuter, Ostrom, Roundtree, \& Bitner, 2000; Seiders, Berry, \& Gresham, 2000). Aside from that, browsing, connection, transfer, analysis, and convenience of possession are the foremost important cause and advantages of conveniences in online business services (Hanus, 2016). The foremost convenient for users is once they can order from home and have all the food delivered which can reduce the user's time to go to the place (Verhoef \& Langerak, 2001). Convenience and consumer satisfaction are found to be correlated as convenience affects the pleasure of leisure and delight of the users, which can influence their loyalty (Dhurup et al., 2006).

\section{Need for Interaction}

The need for interaction refers to the need to interact with others. Consumers do place a strong value on interaction with other human beings for instance service workers and considered that as part of the dining experience (Rawat \& Garga, 2012). The need for interaction for some consumers does not confined to interaction with service personnel but also the interaction with other consumers and some are even looking forward to the pleasure of bargaining before acquiring a new product (Hanus, 2016). With the development of technology, the definition of interaction has also evolved. The interaction today is not limited to human interaction but rather interacts with technology (Rawat \& Garga, 2012). Different from conventional interactions with humans, the interaction for technology is often confined to the area of convenience navigation, the time-saving attribute, and easy-to-use application offer by the use of technology (Dhurup et al., 2006).

\section{Technology Anxiety}

A previous study by Rawat and Garga (2012) found that technology anxiety can impact consumer satisfaction negatively, where certain users can experience anxiety while dealing with technology applications and financial payments. Technology anxiety may cause problems regarding the present activity to be done, decreased confidence levels, and a reduced sense of ability (Curran, Meuter, \& Surprenant, 2003). Furthermore, technology anxiety was found to features a strong impact on consumer's willingness to use online delivery. This is often thanks to their reluctance to undertake out a web self-service application and that they are scared of getting trapped in technology. Hence for a few consumers who face technology anxiety, they still like better to pay delivery in cash once they ordering food instead of using online banking (Rawat \& Garga, 2012). In order to scale back technology anxiety, the applications of the web system need to be easier to access, the merchandise that was ordered got to be accurate, and most significantly the delivery and therefore the availability of the merchandise need to be because it stated within the application. This will help in gaining trust and therefore the consumer will feel more encouraged in using online services (Kimes, 2011).

\section{Satisfaction}

Customer satisfaction is described as the number of users or the percentage of total consumers whose recorded satisfaction with a business, its goods, or its services satisfies the satisfaction objectives. Consumer experience and expectations with the services or products have a connection between consumer satisfactions (Zeithaml et al, 1996). To measure success in delivering satisfaction as consumer satisfaction, the quality of service should be the main focus. Throughout service level delivery with good food, it's going to improve consumer satisfaction which affects consumer loyalty (Ilham, 2018). Furthermore, the profit of a business is strongly associated with customer satisfaction (Best, 2005). Thus, to realize consumers loyalty, satisfaction is a crucial element in online business as consumers can easily switch to competitors if they're dissatisfied with the services given. Therefore, online business or online services has got to keep consumer's satisfaction and royalty to create a successful customer relationship (Nigel \& Jim, 2006).

\section{Behavioral Intention}

Intentions are defined by attitudes towards the behavior and it's also show a sign of consumers' readiness to perform the behavior. Attitudes and subjective norms are determined by the many beliefs 
people hold about the behavior (Asraar Ahmed \& Sathish, 2017). Behavioral intentions are the results of the satisfaction process which will be categorized into two groups which are social behavior and economic behavior (Lyon \& Powers, 2004). Kuruuzum \& Koksal, (2010) in their study revealed that behavior intentions are often measured by positive word of mouth, willingness to recommend and repurchase intentions. As contested by Maiyaki \& Mokhtar (2012), the unfavorable intention features a higher probability which will lead the customer to modify brand, engage in negative word of mouth, and unwillingness to pay a particular amount of cash. Moreover, the satisfaction process is an outcome of the behavioral intention because consumer intention can impact the financials of the corporate especially when the buyer is satisfied with the merchandise and still repeat the acquisition and willing to pay more on the purchasing of the merchandise (Lyon \& Powers, 2004). Thus, it's important to gain consumer satisfaction to create consumer loyalty and building a long-term relationship (Khazaei, Manjiri, Samiey, \& Najafi, 2014).This study suggests the decomposition of the Theory of Reasoned Action and the framework shown in Figure 1 is adopted from Kimes (2011) work.

Figure 1: Conceptual Framework (Kimes, 2011)

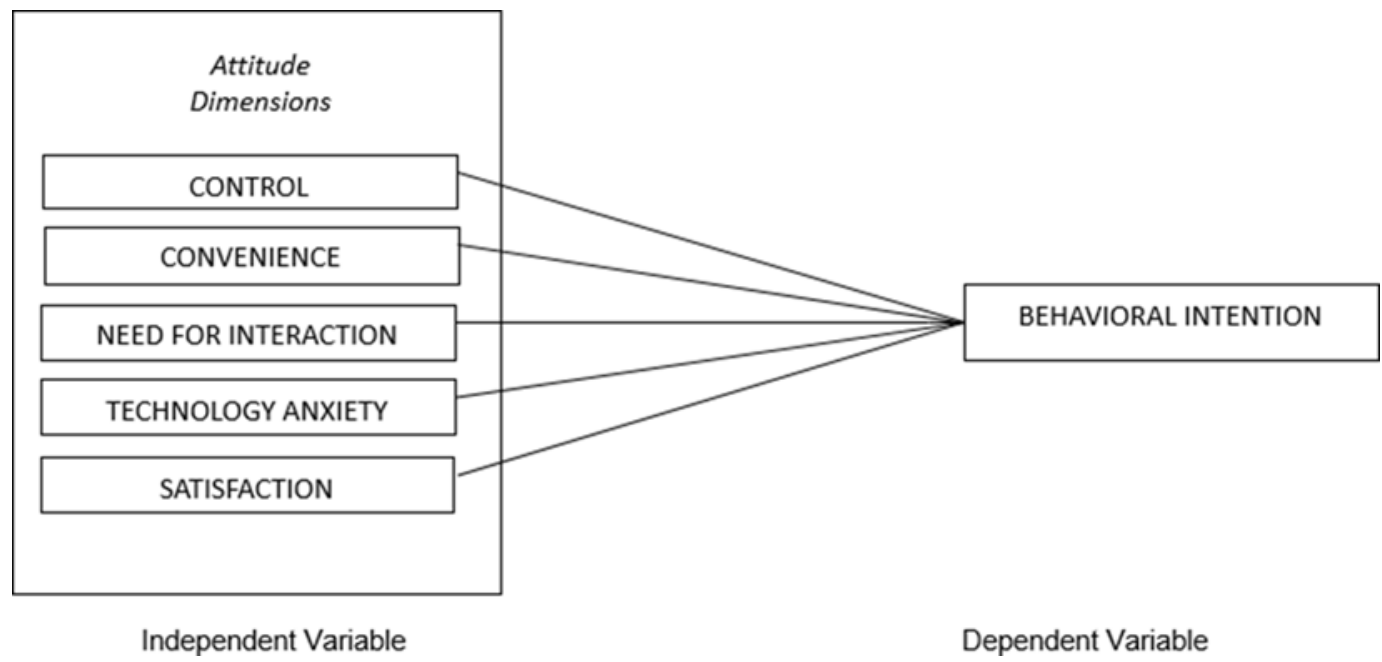

\section{Methodology}

This study is carried out using quantitative research involving the construction of statistical models in an attempt to explain what is observed. Questionnaires were distributed all over Malaysia via online mediums such as email, WhatsApp, and telegram using purposive sampling. Screening questions on whether the potential respondents have engaged in online delivery services were also carried out to eliminate samples that are not part of the sampling frame. Power analysis was used by the researcher to decide on the number of samples to approach because actual numbers of the population involved with online delivery purchase cannot be determined as such data are not available at the time of this study. Based on the power calculation minimum sample size are 138 respondents.

\section{Results}

\section{Reliability Analysis}

Following Sekaran and Bougie (2013), Cronbach's Alpha was used to measure the reliability of a questionnaire. It normally ranges between 0 and 1. If the Cronbach's Alpha Coefficient results are nearer to 1.0, the internal consistency of the items in the scale will be larger. The Cronbach's Alpha for all items is as shown in Table 1. The control and convenience subscale were found to have good internal stability. The need for interaction was found to be acceptably reliable. Meanwhile, technology anxiety, satisfaction, and behavioral intentions were found to be highly reliable. 
DOI: https://doi.org/10.47405/mjssh.v6i9.972

Table 1: Cronbach's Alpha

\begin{tabular}{lcc}
\hline \multicolumn{1}{c}{ Item } & Items (N) & Cronbach's Alpha \\
\hline Control & 4 & .848 \\
Convenience & 4 & .868 \\
Need for interaction & 3 & .773 \\
Technology anxiety & 4 & .919 \\
Satisfaction & 4 & .935 \\
Behavioral intentions & 2 & .921 \\
\hline
\end{tabular}

\section{Demographic Profile}

The questionnaire was designed in two sections. within the demographics section, there have been a complete of five variables which are age, gender, state, preferred online service provider, and frequency of online delivery. There are $4.1 \%$ respondents age below 20, $46.3 \%$ respondents age between 21-30 years old, 26.5\% respondents age between 31-40 years old, $13.6 \%$ respondents age between 41-50 years old, and 9.5\% respondents age above 50 years old. Besides, there are $59.18 \%$ female respondents and $40.82 \%$ male respondents. A complete of 147 respondents that answer this survey are using the delivery service provider as follows; the respondents that are using Food Panda are 68.7\%, Grab Food are 23.8\%, Delivery Eat are 5.4\%, and Dah Makan 2.0\%. Meanwhile, the respondents who use this delivery service provider daily are $10.2 \%$, weekly are $27.9 \%$, a fortnight are $19 \%$ and monthly are $42.9 \%$.

\section{Pearson Correlation Analysis}

The objective of this study is to examine whether there is a significant relationship between intentions, need for interaction, control, convenience, technology anxiety, and satisfaction. Hence, a Pearson Correlation analysis has been done to analyze the result.

Table 2: Pearson Correlation between Consumer Attitudes and Purchase Intention

\begin{tabular}{lllllll}
\hline & Int & $\begin{array}{c}\text { Need } \\
\text { Intro. }\end{array}$ & Control & Convenience & $\begin{array}{l}\text { Tech. } \\
\text { anxiety }\end{array}$ & Satisfaction \\
\hline Intention & 1 & $.421^{* *}$ & $.502^{* *}$ & $.540^{* *}$ & $-.289^{* *}$ & $.757^{* *}$ \\
Need interaction & & & .437 & .538 & -.042 & .456 \\
Control & & & & .685 & -.129 & .507 \\
Convenience & & & & & -.080 & .517 \\
Technology Anxiety & & & & & & $-.249^{*}$ \\
Satisfaction & & & & & & \\
\hline
\end{tabular}

As shown in Table 2, by using the Pearson correlation method, analysis of 147 respondents revealed that there was a significant positive relationship between intention and need for interaction $(r=0.421$, $\mathrm{n}=147, \mathrm{p}<.000)$ but has inversed relationship with technology anxiety $(\mathrm{r}=-0.289, \mathrm{n}=147, \mathrm{p}<.000)$. This means that the lower the technology anxiety, the higher online purchase intention. The relationship became stronger and more significant with correlation coefficients for control, convenience, and satisfaction increasing to $0.502,0.540$, and 0.757 respectively, all was significant at the 0.000 level. The results show that the higher the control, convenience, and satisfaction, the higher the online purchase intention would be.

There was a significant positive relationship between the need for interaction and intention, control, convenience, and satisfaction with correlation coefficients $(\mathrm{r}=0.421,0.437,0.538$, and 0.456) respectively which was significant at the 0.000 level but does not correlate with technology anxiety. As for control, there was a positive relationship between control and intention, need for interaction, convenience, and satisfaction with correlation coefficients $(r=0.502,0.437,0.685$, and 0.507) respectively which was significant at the 0.000 level but has no relationship with technology anxiety. 
There was also a significant positive relationship between convenience and intention, need for interaction, control, and satisfaction with correlation coefficients $(\mathrm{r}=0.540,0.538,0.685$, and 0.507$)$ respectively which was significant at the 0.000 level but has no relationship with technology anxiety. As for technology anxiety, there was a negative relationship between technology anxiety and intention with correlation coefficients $(r=-0.289)$ which was significant at the 0.000 level, $(r=-0.249, p<0.01)$ for satisfaction. Lastly, there was a significant positive relationship between satisfaction and intention, need for interaction, control, and convenience with a correlation coefficient $(r=0.757,0.456,0.507$ and 0.517) respectively which was significant at the 0.000 level but a negative relationship with technology anxiety with a coefficient of correlation $(r=-0.249)$ and significant at 0.01 level.

\section{Discussion}

Intention to purchase food through an online food delivery provider has a strong correlation with satisfaction which an indication that the respondents are comfortable in using this service as the majority of respondents who participated in this study are those who are below 40 years old. The wide ranges of age gap range from Generation $\mathrm{Z}$ to Generation $\mathrm{X}$ also provide a strong indication on how the future trend of delivery service in Malaysia. The convenience attribute offers by online delivery has become another important characteristic that becomes the attraction for the vast majority of respondents including those from Generation $X$ as the majority of this age group are family with children. Hence, ordering take-out has become easier with the wide range of foods offering online. Time-saving quality has become one of the critical attributes that becoming the main predictor in food decision making especially for working parents. Despite delivery service has been around for so long, however, such services are often limited to certain restaurants especially quick-service restaurants which is also the reason why a family with children often becomes the target segment for businesses.

Apart from that, the ability to control and in control is another feature that is important that determining a respondent's intention to purchase from an online service delivery providers. Therefore, it indicates that the consumers still fell in control of what they purchase and felt comfortable when making a purchase. Inversed relationship between technology anxiety indicates that some of the respondents does faced with difficulties when using the service delivery application. However, with the low inversed relationship between technology anxiety and intention, one can hypothesize that not all respondents shared similar believes when it comes to technology anxiety and some respondents might find it difficult to navigate this application. This is not a surprise finding particularly when looking at the distribution of age gap and distribution of generational segment in the samples. Apart from that, the need for interaction also provides future research with evidence on how current and future consumers will behave. It is quite obvious that these consumers have challenged the long-standing notion of service and ambiances are part of the crucial experience when enjoying food. It is interesting to see why such segment who are purposely looking for less interaction does exist and judging by the popularity of third-party delivery service such segment has grown significantly over the years. The changes in the population structure and dynamic couple with long working hours have led to the emergence of this new segment in the market. Apart from that, changes in consumer behavior have also created a new opportunity for new businesses to compete in the market without the need for higher investment especially on the physical restaurant as the element of servicescape is no longer part of the determinant in consumers' purchase intention.

\section{Conclusion}

Current findings offer new perspectives on consumer's intention in using online service delivery providers. This finding has become more important during movement control order (MCO) due to the physical restriction imposed on restaurant dining activities. Besides, a new market segment has evolved since there are needs for social distancing where people will choose for no interaction services and additionally with intention to comply with MCO policy. Thus, service providers should improve their online delivery services. Improvement should not be limited to delivery time but improvement to simplified application and design which could elevate the application usage from the technology 
anxiety segment. Besides, after the Covid-19 pandemic hit, QR code usage had increased, and because of social distancing requirement, the demand for online service delivery would grow higher. There is more application such as E-wallet had contributed to the disruption of online delivery service. Further study can be carried out on whether cashless transactions will continue to gain their momentum after the post-Covid-19 pandemic. Go cashless scenario will continue as a norm in post-pandemic situation with the identification of new segment who are looking for less interaction. In a nutshell, ghost kitchen is believed to rise in the future as physical dining experience has been eliminated with the rapid growth of third-party online delivery services. Future research on online service providers also should expand their research scope on other products as well including non-food products as decision making, purchase intention and involvement are different in these products. Hence, it will help to extend the body of knowledge concerning the online service delivery business and its profiling segment.

\section{References}

Acumen Research and Consulting (2021). Malaysia Online Food Delivery Market - Industry Analysis, Market Size, Opportunities and Forecast, 2018 - 2026. Retrieved from https://www.acumenresearchandconsulting.com/malaysia-online-food-delivery-market

Ajzen, I. (1991). The Theory of Planned Behavior. Organizational Behavior and Human Decision Processes, 50, 179-211.

Asraar Ahmed \& Sathish. (2017). Determinants of behavioral intention, user behavior, and addiction towards social network games among Indian college students. Man in India. 97(4), 21-42.

Best. (2005). Market-based management. In R. J. Best, Strategies for growing customer value and profitability (pp. 7-20). New Jersey: Pearson Prentice Hall.

Chang YW, Polonsky MJ, 2012. The influence of multiple types of service convenience on behavioral intentions: the mediating role of consumer satisfaction in Taiwanese leisure setting. International Journal of Hospitality Management. 31: 107-118.

Chorneukar, M. J. (2014). To Study the Customer Perceptions of Electronic Food Ordering. St. Joseph's Evening College - Pondicherry University Twinning Programme Pondicherry 605014 , Batch $(2012-2014)$ revealed from http://Www.Sjput.In/Pdf/lMarketing\%20sample\%20project.Pdf

Curran, J. M., Meuter, M. L., \& Surprenant, C. F. (2003). Intentions to Use Self-Service Technologies: A Confluence of Multiple Attitudes. Journal of Service Research, 5(3), 209-224. https://doi.org/10.1177/1094670502238916

Das, J. (2018). Consumer Perception Towards 'Online Food Ordering and Delivery Services ': An Empirical Study. Journal of Management, 5(5), 155-163.

Dhurup M, Singh C, Surujlal J, 2006. Application of the health and fitness service quality scale (HAFSQ) in determining the relationship between service quality, satisfaction, and loyalty in the service industry. African Journal for Physical Health Education, Recreation \& Dance. 12(3), 238-251

Gawande, Pachaghare, \& Deshmukh. (2019). A Study of Customer Perception about Online Food Ordering Services in Amravati City Ninad. International Journal of Latest Technology in Engineering, Management \& Applied Science. 7(4), 114-116.

Gigerenzer, G., \& Gaissmaier, W. (2011). Heuristic decision making. Annual review of psychology, $62,451-482$.

Hanus, G. (2016). Consumer Behaviour During Online Grocery Shopping. CBU International Conference Proceedings, 4, 010-013. https://doi.org/10.12955/cbup.v4.737

Huang, Y., \& Oppewal, H. (2006). Why consumers hesitate to shop online. An experimental choice analysis of grocery shopping and the role of delivery fees. International Journal of Retail \& Distribution Management, 34 (4/5), 334-353.

Ilham, R. (2018). Improve Quality Of E-Loyalty In Online Food Delivery Services: A Case Of Indonesia. Journal of Theoretical and Applied Information Technology, 96(15), 4760-4769.

Jacob, Sreedharan, \& Sreena. (2019). Consumer Perception of Online Food Delivery Apps in Kochi. International Journal of Innovative Technology and Exploring Engineering, 8(7), 302-305.

Johnson. (2001). The evolution and future of national customer satisfaction models. Journal of Economic Psychology, 22(2), 217-245. 
Kamoto, N. (2000). Language learning strategy and personality variables: Focusing on extroversion and introversion. IRAL - International Review of Applied Linguistics in Language Teaching, 38(1), 71-81. https://doi.org/10.1515/iral.2000.38.1.71

Karpińska-Krakowiak, M. (2014). Consumer behavior while grocery shopping on-line - research propositions. Marketing I Rynek 6, 20-26.

Khazaei, A., Manjiri, H., Samiey, E., \& Najafi, H. (2014). The Effect of Service Convenience on Customer Satisfaction and Behavioral Responses in Bank Industry. International Journal of Basic Science \& Applied Research, 3(1), 16-23.

Kimes, S. E. (2011). Customer Perceptions of Electronic Food Ordering. Cornell Hospitality Report, $11(10), 6-15$.

Kuruuzum A, Koskal CD, (2010). The impact of service quality on behavioral intention in hospitality industry. International Journal of Business and Management Studies. 2(1): 9- 15

Lan, H., Ya, L. I., \& Shuhua, W. (2016). Improvement of Online Food Delivery Service Based on Consumers , Negative Comments, Canadian Social Science, 12(5), 84-88. https://doi.org/10.3968/8464

Lyon DB, Powers TL, (2004). The impact of structure and process attributes on satisfaction and behavioral intentions. Journal of Services Marketing. 18(2): 114-121.

Maiyaki AA, Mokhtar SSM, (2012). Determinants of customer behavioural responses in the Nigerian banks: structural equation modeling approach. African Journal of Business Management. 6(4): 1652-1659.

Meuter, M. L., Ostrom, A. L., Roundtree, R. I., \& Bitner, M. J. (2000). Self-service technologies: Understanding customer satisfaction with technology-based service encounters. Journal of Marketing, 64,50-64, (July).

Nigel, H., \& Jim, A. (2006). The Handbook of customer satisfaction and Loyalty Measurement (3rd ed.). Gower Publishing Company Paul, J.; Modi, A.; Patel, J. Predicting green product consumption using theory of planned behavior and reasoned action. J. Retail. Consum. Serv. 2016, 29, 123-134.

Pigatto ,G., Machado, J.G., Negreti, A., Machado „L.. (2017). Have you chosen your request? Analysis of online food delivery companies in Brazil, Brazil Food Journal, 119 (3), 639-657

Rathore, S. S., \& Chaudhary, M. (2018). Consumer 's Perception on Online Food Ordering. International Journal of Management \& Business Studies, 9519, 12-17. Retrieved from http://www.ijmbs.com/Vol8/issue4/2-suryadev-singh-rathore.pdf

Rawat, S. R., \& Garga, P. K. (2012). Understanding Consumer Behaviour Towards Green Cosmetics. SSRN Electronic Journal, 97(16), 4353-4365. https://doi.org/10.2139/ssrn.2111545

Sekaran, U., \& Bougie, R. (2013). Research Methods for Business: A Skill-Building Approach. 6th Edition, Wiley, New York.

Tan, D. (2019, November 11). Food delivery firm delivers on growth. The Star Online, pp. 11-14. Retrieved from https://www.thestar.com.my/business/smebiz/2019/11/11/food- delivery-firmdelivers-on-growth

Verhoef, P., \& Langerak, F. (2001). Possible determinants of consumers' adoption of electronic grocery shopping in the Netherlands. Journal of Retailing and Consumer Services, 8, 275-285.

Vogels, E.A. (2019). "Millennials stand out for their technology use, but older generations also embrace digital life" Pew Reseacrh Center. Washington, DC, USA. Retrieved from https://www.pewresearch.org/fact-tank/2019/09/09/us-generations-technology-use/

Zeithaml VA, Berry LL, Parasuraman A. (1996). The behavioral consequences of service quality. Journal of Marketing Research, 60(2): 31-46. 